\title{
NILAI NORMAL LATENSI DAN AMPLITUDO GELOMBANG VISUAL EVOKED POTENTIAL PADA USIA DEWASA
}

\author{
NORMATIVE VALUES OF VISUAL EVOKED POTENTIALS'LATENCIES AND AMPLITUDES \\ IN ADULTS
}

Ade Wijaya, * Manfaluthy Hakim, * Nurhadi Ibrahim, ** Joedo Prihartono***

\section{ABSTRACT}

Introduction: Visual evoked potentials (VEP) is used to assess the visual pathway through the optic nerves and brain. VEP wave can be affected by physiological and non-physiological factors; some of which can be controlled, while others cannot. Thus, each VEP laboratory needs its own set of normative values. A normal VEP response to a stimulus is a positive occipital peak that occurs at a mean latency of $100 \mathrm{~ms}$. Most of the published normal value originated from abroad where demographical and environment condition are considered less appropriate with Indonesian population.

Aims: To established normal value of adult VEP latency and amplitude in Clinical Naeurophysiology Laboratorium, Neurology Clinic Dr. Cipto Mangunkusumo Hospital, Jakarta.

Method: A cross-sectional study on healthy subject between 18 to 55 years old. The anthropometric parameters including age, height, weight, body mass index and head circumference were recorded in all the subjects. VEP was recorded with a Caldwell Sierra Summit machine and standard silver-silver chloride disc electrodes. A VEP monitor displaying checker board was used to give the pattern reversal stimulus. The VEP parameters recorded were latencies to P100 waves.

Results: P100 latencies on 110 subjects, 55 male, and 55 female upon recording at 32' check size were $117 \mathrm{~ms}$ in male and $119 \mathrm{~ms}$ in female. Upper normal limit of interocular latency difference values in recording at the same size were 10,96ms in male and 10,2ms in female. No significant differences of P100 latencies between male and female were found, but there were significant differences in amplitudes.

Discussion: In our population, gender is an important factor affecting P100 amplitudes but not P100 latencies.

Keywords: Amplitude, latency, P100, visual evoked potential

\section{ABSTRAK}

Pendahuluan: Visual evoked potentials (VEP) digunakan untuk menilai jaras visual dari nervus optikus hingga korteks visual. Gelombang VEP dapat dipengaruhi oleh berbagai faktor fisiologis dan non-fisiologis yang tidak semua dapat dikontrol, sehingga diperlukan referensi nilai normal latensi dan amplitudo gelombang VEP untuk di setiap laboratorium. Sejauh ini mayoritas referensi berasal dari studi di luar negeri yang secara demografi maupun kondisi setempat dapat kurang sesuai dengan populasi di Indonesia.

Tujuan: Mengetahui nilai normal latensi dan amplitudo gelombang VEP pada subjek dewasa di Laboratorium Neurofisiologi Klinik, Poliklinik Saraf RSUPN Dr. Cipto Mangunkusumo, Jakarta, sebagai referensi pemeriksaan VEP di kemudian hari.

Metode: Studi potong lintang pada subjek sehat berusia antara 18 hingga 55 tahun. Subjek diukur antropometri, seperti usia, tinggi badan, berat badan, indeks massa tubuh, dan lingkar kepala. Perekaman VEP menggunakan alat Caldwell Sierra Summit, dan elektroda elektroensefalografi (EEG) standar. Stimulus VEP menggunakan layar berpola dan metode transient pattern reversal. Parameter VEP yang direkam adalah latensi dan amplitudo P100.

Hasil: Pada perekaman terhadap 110 subjek yang terdiri dari 55 subjek laki-laki dan 55 subjek perempuan dengan ukuran kotak 32', nilai batas atas latensi gelombang P100 adalah $117 \mathrm{~ms}$ pada laki-laki dan $119 \mathrm{~ms}$ pada perempuan. Nilai batas atas perbedaan latensi interokular pada perekaman dengan ukuran kotak yang sama adalah 10,96ms untuk laki-laki dan 10,2ms untuk perempuan. Tidak ada perbedaan bermakna antara latensi gelombang P100 pada kelompok laki-laki dan perempuan, tetapi terdapat perbedaan amplitudo P100 yang bermakna antara kelompok laki-laki dan perempuan.

Diskusi: Terdapat perbedaan yang bermakna pada rerata amplitudo P100 antara subjek laki-laki dan perempuan pada perekaman dengan ukuran kotak 16' maupun 32'.

Kata kunci: Amplitudo, latensi, P100, visual evoked potentials

*Departemen Neurologi FK Universitas Indonesia/RSUPN Dr. Cipto Mangunkusumo, Jakarta; **Departemen Fisiologi Kedokteran FK Universitas Indonesia; ***Departemen Ilmu Kedokteran Komunitas FK Universitas Indonesia. Korespondensi: aquatic_dimenzion@ yahoo.com. 


\section{PENDAHULUAN}

Visual evoked potentials (VEP) adalah sinyal elektrofisiologis yang dicetuskan oleh stimulus visual yang diekstraksi dari aktivitas elektroensefalografi pada korteks visual yang direkam oleh elektroda permukaan. ${ }^{1-2}$ VEP sangat tergantung dari integritas fungsional jaras visual mulai dari mata, retina, nervus optikus, radiasio optika, hingga korteks oksipital. ${ }^{2}$ VEP dapat memberikan informasi diagnosis penting terkait integritas fungsional dari sistem visual. ${ }^{3}$

VEP dapat digunakan untuk mendeteksi berbagai macam kondisi/kelainan yang memengaruhi integritas jaras visual di level prekiasma, kiasma, maupun di belakang kiasma. ${ }^{4-6}$ VEP merupakan modalitas yang sangat sensitif, tetapi kurang spesifik dalam mendeteksi beberapa kasus neurologis tertentu, seperti multipel sklerosis atau glioma nervus optikus. $^{7-12}$ VEP juga sering digunakan untuk menentukan prognosis pada pasien dengan neuropati optik traumatik. ${ }^{13-14}$

Suatu studi nilai normal VEP oleh Chiappa di Amerika pada tahun 1990 mendapatkan rentang latensi gelombang P100 pada kisaran 89-114 milidetik. Adapun studi yang lebih baru di Asia mendapatkan rentang latensi gelombang P100 adalah 79-104 milidetik. ${ }^{6}, 15$ Latensi dan amplitudo gelombang tersebut dipengaruhi oleh berbagai faktor, baik faktor subjek/individu maupun faktor teknis. Faktor subjek antara lain usia, jenis kelamin, lingkar kepala, dan atensi subjek, sedangkan faktor teknis berupa jenis layar stimulus, ukuran kotak stimulus, maupun pencahayaan ruangan., ${ }^{4,6,11}$

Oleh karena banyaknya faktor yang memengaruhi, setiap laboratorium harus memiliki nilai normal VEP masing-masing menggunakan stimulus dan parameter yang dipakai di laboratorium tersebut. ${ }^{2}$ Perbedaan latensi gelombang P100 antara studi di Amerika dan Asia diperkirakan antara lain karena perbedaan ukuran lingkar kepala antar populasi tersebut. Perbedaan antar laboratorium juga dapat disebabkan oleh perbedaan pencahayaan ruangan, sedangkan faktor-faktor lain sebelumnya dapat diseragamkan.

Selama ini pemeriksaan VEP di laboratorium Neurofisiologi Klinik Departemen Neurologi
FKUI/RSUPN Dr. Cipto Mangunkusumo (RSCM) menggunakan referensi dari studi di luar negeri yang secara demografi maupun kondisi setempat dapat kurang sesuai dengan populasi di Indonesia. Oleh karena itu, diperlukan suatu studi untuk menentukan referensi nilai normal latensi dan amplitudo gelombang VEP berdasarkan hasil pengukuran dari populasi setempat.

\section{TUJUAN}

Mengetahui nilai normal latensi dan amplitudo gelombang VEP pada subjek dewasa di Laboratorium Neurofisiologi Klinik, Poliklinik Saraf RSCM, Jakarta, sebagai referensi pemeriksaan VEP di kemudian hari.

\section{METODE}

Studi ini dilakukan secara potong lintang terhadap subjek sehat berusia 18-55 tahun di Laboratorium Neurofisiologi Klinik, Poliklinik Saraf RSCM, Jakarta, pada bulan September hingga Desember 2016. Perekrutan pasien dilakukan secara non-random sampling sampai jumlah sampel terpenuhi. Studi ini telah lolos kaji etik studi FKUI dan setiap subjek studi dimintakan persetujuan tertulis. Subjek yang memiliki riwayat kelainan neurologis intrakranial, riwayat konsumsi alkohol rutin, penyakit ginjal kronik, penyakit tiroid, penyakit keganasan, epilepsi, penyakit mata (katarak, glaukoma, retinopati, atrofi optik), diabetes, merokok, gangguan kejiwaan dan tumbuh kembang berdasarkan anamnesis tidak diikutsertakan ke dalam studi. Demikian pula subjek yang mengkonsumsi obat-obat seperti antidepresan, antipsikotik, sedatif, dan opioid dalam 1 bulan terakhir, serta subjek dengan penurunan kesadaran atau subjek yang tidak kooperatif juga dieksklusi. Subjek harus memiliki ketajaman penglihatan lebih dari 20/200 dengan lensa korektif terbaik serta memiliki lapang pandang dan hasil pemeriksaan funduskopi yang normal.

Parameter antropometrik seperti usia, tinggi badan, berat badan, indeks massa tubuh, serta lingkar kepala dan juga visus pasien dicatat selama studi. Pengukuran lingkar kepala dilakukan dengan menggunakan meteran yang melalui supraorbital dan bagian yang paling menonjol di oksipital. Pemeriksaan visus dilakukan dengan Rosenbaum Visual Acuity Card. Pemeriksaan lapang pandang 
dilakukan dengan teknik konfrontasi dan pemeriksaan lapang pandang sentral dengan menggunakan Amsler grid. Pemeriksaan funduskopi dilakukan dengan oftalmoskopi direk. Penyakit/kondisi yang memengaruhi studi disingkirkan dengan anamnesis/ kuesioner dan pemeriksaan fisik.

Pemeriksaan VEP dilakukan dengan alat Caldwell Sierra Summit menggunakan layar LCD ViewSonic VT2216-L diameter 24 inci yang telah dikalibrasi secara digital untuk menghilangkan efek pemanjangan latensi. Subjek diminta untuk fokus, tetapi rileks selama pemeriksaan. Pemeriksaan VEP dilakukan secara monokular pada setiap mata dengan kontras tinggi $>50 \%$ menggunakan checkerboard hitam putih dengan frekuensi 4Hz. Jarak subjek dengan layar $100 \mathrm{~cm}$ dengan fiksasi visual pada tengah layar stimulus. Pemeriksaan dilakukan dengan VEP pola, pattern-reversal, transien dengan ukuran kotak 16 ' dan 32'.

Perekaman dengan sistem bandpass dengan filter tidak lebih dari $12 \mathrm{~dB} /$ oktaf. Waktu analisis 250 milidetik. Perekaman minimal dilakukan 2 kali dengan 200 stimuli per perekaman. Penempatan elektroda dengan metode Queen Square dan impedans tiap elektroda dibawah 5Ohm. Perekaman dilakukan dalam ruangan bercahaya redup, tanpa ada sumber cahaya terang lain yang dapat mengalihkan fokus subjek. Pencahayaan ruangan diukur agar berada dibawah $30 \mathrm{Cd} / \mathrm{m}^{2}$ dengan alat lux meter/light meter. Ruangan dikondisikan tenang tanpa adanya sumber suara yang dapat mencetuskan gelombang brainstem auditory evoked potentials (BAEP) atau mengganggu fokus subjek.
Analisis data menggunakan program SPSS versi 17.0. Hubungan antar variabel dianggap bermakna bila $\mathrm{p}<0,05$ dan interval kepercayaan 95\%. Pada data numerik dilakukan uji normalitas data menggunakan uji Kolmogorov-Smirnov atau Shapiro-Wilk dan dilakukan upaya transformasi data untuk menormalkannya bila distribusi tidak normal. Data numerik disajikan dalam bentuk nilai rerata dan simpang baku jika distribusinya normal, serta bentuk median dengan rentang nilai jika distribusinya tidak normal.

\section{HASIL}

Didapatkan 110 subjek normal (Tabel 1) yang terdiri dari masing-masing 55 orang lakilaki dan perempuan dengan rerata usia $29,7 \pm 6,374$ tahun. Pemeriksaan dilakukan ada ruangan dengan pencahayaan redup dengan rerata pencahayaan ruangan $20,03 \pm 6,827 \mathrm{Cd} / \mathrm{m}^{2}$.

Studi ini mengukur nilai tengah/rerata latensi (dalam milidetik) gelombang N70, P100, dan N 145, amplitudo gelombang P100, jarak antara puncak N75 dengan P100 (dalam mikrovolt), serta rasio amplitudo interhemisfer dan interokular juga perbedaan latensi interokular pada masing-masing kelompok jenis kelamin, laki-laki dan perempuan. Perekaman dilakukan menggunakan ukuran kotak 16' dan 32' (Tabel 2 dan Tabel 3). Tidak didapatkan perbedaan rerata latensi gelombang P100 yang bermakna (nilai $p>0,05$ ) antara subjek laki-laki dan perempuan, tetapi terdapat perbedaan yang bermakna pada rerata amplitudo P100 antara subjek laki-laki dan perempuan pada perekaman dengan ukuran kotak 16 ' maupun 32'.

Tabel 1. Karakteristik Subjek Penelitian $(n=110)$

\begin{tabular}{lccc}
\hline \multicolumn{1}{c}{ Parameter } & $\begin{array}{c}\text { Laki-laki } \\
\text { Median (min-maks) } \\
\text { /rerata } \pm \text { SD }\end{array}$ & $\begin{array}{c}\text { Perempuan } \\
\text { Median (min-maks) } \\
\text { /rerata } \pm \text { SD }\end{array}$ & p* \\
\hline Usia (tahun) & $29,69 \pm 7,102$ & $29,71 \pm 5,62$ & 0,176 \\
Tinggi badan $(\mathrm{cm})$ & $168,65 \pm 5,697$ & $157,98 \pm 5,858$ & 0,000 \\
Berat badan $(\mathrm{kg})$ & $67,02 \pm 13,004$ & $55,56 \pm 9,418$ & 0,000 \\
Indeks massa tubuh $\left(\mathrm{kg} / \mathrm{m}^{2}\right)$ & $23,52 \pm 4,2605$ & $22,26 \pm 3,4895$ & 0,200 \\
Lingkar kepala $(\mathrm{cm})$ & $56,07 \pm 2,332$ & $54,89 \pm 1,397$ & 0,002 \\
Visus & $20 / 20(20 / 20-20 / 100)$ & $20 / 20(20 / 20-20 / 70)$ & 0,000 \\
\hline
\end{tabular}

*Uji Mann-Whitney; SD: standar deviasi. 
Tabel 2. Rerata dan Nilai Tengah Pemeriksaan VEP dengan Ukuran Kotak 16' (n=110)

\begin{tabular}{|c|c|c|c|c|c|}
\hline Parameter & $\begin{array}{c}\text { Laki-laki } \\
(\text { rerata } \pm S D)\end{array}$ & $\begin{array}{l}\text { Perempuan } \\
\text { (rerata } \pm \text { SD) }\end{array}$ & $\begin{array}{c}\text { Laki-laki } \\
\text { (median; min-maks) }\end{array}$ & $\begin{array}{c}\text { Perempuan } \\
\text { (median; min-maks) }\end{array}$ & p* \\
\hline Latensi P100 (ms) & $105,25 \pm 6,8570$ & $105,42 \pm 6,6372$ & & & 0,992 \\
\hline Latensi N75 (ms) & $77,90 \pm 5,3681$ & $77,84 \pm 6,0281$ & & & 0,997 \\
\hline Latensi N145 (ms) & $144,24 \pm 11,6149$ & $147,52 \pm 10,8253$ & & & 0,009 \\
\hline Amplitudo P100 (mV) & & & $6,53(2,05-13,76)$ & $10,81(3,35-27,17)$ & 0,000 \\
\hline $\begin{array}{l}\text { Rasio amplitudo } \\
\text { interhemisfer }\end{array}$ & & & $1,42(1-3,37)$ & $1,46(1-3,4)$ & 0,521 \\
\hline $\begin{array}{l}\text { Rasio amplitudo } \\
\text { interokular }\end{array}$ & $1,27 \pm 0,2189$ & $1,22+0,2501$ & & & 0,098 \\
\hline $\begin{array}{l}\text { Perbedaan latensi } \\
\text { interokular }\end{array}$ & & & $3,9(0,3-16)$ & $2,5(0-15,7)$ & 0,020 \\
\hline
\end{tabular}

*Uji Mann-Whitney; VEP: visual evoked potential; SD: standar deviasi. ms: milidetik; mV: milivolt.

Tabel 3. Rerata dan Nilai Tengah Pemeriksaan VEP dengan Ukuran Kotak 32' (n=110)

\begin{tabular}{|c|c|c|c|c|c|}
\hline Parameter & $\begin{array}{c}\text { Laki-laki } \\
\text { (rerata } \pm \text { SD) }\end{array}$ & $\begin{array}{l}\text { Perempuan } \\
\text { (rerata } \pm \text { SD) }\end{array}$ & $\begin{array}{c}\text { Laki-laki } \\
\text { (median; min-maks) }\end{array}$ & $\begin{array}{c}\text { Perempuan } \\
\text { (median; min-maks) }\end{array}$ & $\mathbf{p}^{*}$ \\
\hline Latensi P100 (ms) & $100,19 \pm 5,6529$ & $101,05 \pm 5,7939$ & & & 0,843 \\
\hline Latensi N75 (ms) & $72,66 \pm 4,6790$ & $73,98 \pm 5,4098$ & & & 0,021 \\
\hline Latensi N145 (ms) & $140,08 \pm 10,8491$ & $142,85 \pm 11,2990$ & & & 0,109 \\
\hline Amplitudo P100 (mV) & & & $7,50(2,93-17,68)$ & $10,40(2,43-26,09)$ & 0,000 \\
\hline $\begin{array}{l}\text { Rasio amplitudo } \\
\text { interhemisfer }\end{array}$ & & & $1,40(1-2,9)$ & $1,32(1-3,67)$ & 0,604 \\
\hline $\begin{array}{l}\text { Rasio amplitudo } \\
\text { interokular }\end{array}$ & $1,3 \pm 0,2947$ & $1,25 \pm 0,2145$ & & & 0,592 \\
\hline $\begin{array}{l}\text { Perbedaan latensi } \\
\text { interokular }\end{array}$ & & & $3,7(0,4-14,3)$ & $3,2(0,2-13,1)$ & 0,471 \\
\hline
\end{tabular}

*Uji Mann-Whitney; VEP: visual evoked potential; SD: standar deviasi; ms: milidetik; mV: milivolt.

Tabel 4. Hubungan antara Latensi dan Amplitudo P100 terhadap Ukuran Kotak VEP (n=110)

\begin{tabular}{llll}
\hline & \multicolumn{1}{c}{ Ukuran kotak 16' } & \multicolumn{1}{c}{ Ukuran kotak 32' } & $\mathbf{p}^{*}$ \\
\hline Latensi P100 laki-laki (ms) & $105,25 \pm 6,8570$ & $100,19 \pm 5,6529$ & 0,000 \\
Latensi P100 perempuan (ms) & $105,42 \pm 6,6372$ & $101,65 \pm 5,7939$ & 0,000 \\
Amplitudo P100 laki-laki (mV) & $6,53(2,05-13,76)$ & $7,50(2,93-17,68)$ & 0,054 \\
Amplitudo P100 perempuan (mV) & $10,81(3,35-27,17)$ & $10,40(2,43-26,09)$ & 0,979 \\
\hline
\end{tabular}

*Uji Mann-Whitney; VEP: visual evoked potential; ms: milidetik; mV: milivolt.

Tidak didapatkan perbedaan rerata amplitudo gelombang P100 yang bermakna $(\mathrm{p}>0,05)$ antara perekaman dengan ukuran kotak 16' dan 32', tetapi terdapat perbedaan yang bermakna pada rerata latensi P100 antara perekaman dengan ukuran kotak 16' dan 32'pada subjek laki-laki maupun perempuan (Tabel 4).

Tabel 5 memperlihatkan nilai batas atas dari latensi gelombang P100, perbedaan latensi interokuler, serta rasio amplitudo gelombang VEP. Nilai batas atas ini (rerata $+3 \mathrm{SD} /$ persentil 95) dihitung sesuai dengan standar International Federation of Clinical Neurophysiology (IFCN) dan American Electroencephalography Society (AES) yang dapat digunakan sebagai acuan dalam menentukan nilai normal pada pemeriksaan VEP.

Sebagai data tambahan, dihitung juga korelasi antara parameter antropometri dan visus dengan 
Tabel 5. Nilai Batas Atas Parameter VEP pada Perekaman dengan Ukuran Kotak 16' dan 32'

\begin{tabular}{lcc}
\hline \multicolumn{1}{c}{ Satuan dalam milidetik } & Nilai batas atas 16' & Nilai batas atas 32' \\
\hline Latensi P100 laki-laki (ms) & 126 & 117 \\
Latensi P100 perempuan (ms) & 125 & 119 \\
Perbedaan latensi interokular P100 laki-laki & 10,32 & 10,96 \\
Perbedaan latensi interokular P100 perempuan & 11,14 & 10,2 \\
Rasio amplitudo interhemisfer laki-laki & 2,97 & 2,49 \\
Rasio amplitudo interhemisfer perempuan & 2,53 & 2,55 \\
Rasio amplitudo interokular laki-laki & 1,93 & 2,18 \\
Rasio amplitudo interokular perempuan & 1,97 & 1,89 \\
\hline
\end{tabular}

Rerata +3 SD/persentil 95; VEP: visual evoked potential; ms: milidetik; mV: milivolt.

latensi serta amplitudo gelombang P100 (Tabel 6).

Dari hasil perhitungan ini didapatkan korelasi yang bermakna antara berat badan dan tinggi badan dengan amplitudo P100, serta didapatkan pula korelasi yang bermakna antara lingkar kepala dan visus dengan amplitudo P100 pada perekaman menggunakan ukuran kotak 16,
$91,07 \pm 49 \mathrm{~ms}$ pada perempuan dan $95,37 \pm 6,85 \mathrm{~ms}$ pada laki-laki. ${ }^{15,18}$

Ketiga studi ini dilakukan di Asia menggunakan metode pemasangan elektroda 10/20, walaupun secara teoritis tidak menyebabkan perbedaan bermakna. Studi Tandon menggunakan monitor tabung, sedangkan sudi Sharma dan

Tabel 6. Koefisien Korelasi antara Parameter Antropometri dan Parameter VEP (n=110)

\begin{tabular}{lcccc}
\hline \multicolumn{1}{c}{ Parameter } & $\begin{array}{c}\text { Latensi } \\
\text { P100 (16') }\end{array}$ & $\begin{array}{c}\text { Amplitudo } \\
\text { P100 (16') }\end{array}$ & $\begin{array}{c}\text { Latensi } \\
\text { P100 (32') }\end{array}$ & $\begin{array}{c}\text { Amplitudo } \\
\text { P100 (32') }\end{array}$ \\
\hline Usia & $-0,006$ & 0,068 & 0,056 & $-0,021$ \\
Tinggi badan & $-0,040$ & $\mathbf{- 0 , 3 1 4 *}$ & 0,023 & $\mathbf{- 0 , 2 9 1 *}$ \\
Berat badan & $-0,087$ & $\mathbf{- 0 , 2 4 7 *}$ & 0,020 & $\mathbf{- 0 , 2 4 9 *}$ \\
IMT & 0,00 & $-0,111$ & 0,015 & $-0,130$ \\
Lingkar kepala & 0,097 & $\mathbf{- 0 , 1 9 *}$ & 0,144 & $-\mathbf{0 , 2 3 7 *}$ \\
Visus & $-0,097$ & $\mathbf{- 0 , 1 4 6 *}$ & $-0,044$ & $-0,129$ \\
\hline
\end{tabular}

*Uji Pearson/Spearman; IMT: indeks massa tubuh.

\section{PEMBAHASAN}

Data antropometri (tinggi badan serta lingkar kepala) subjek pada studi ini tidak jauh berbeda dengan data antropometri penduduk Indonesia, sehingga diharapkan dapat digunakan sebagai acuan untuk populasi Indonesia. ${ }^{16-17}$

Pada studi ini, rerata latensi P100 pada subjek perempuan adalah $101,65 \pm 5,794 \mathrm{~ms}$ dan pada lakilaki $100,19 \pm 5,653 \mathrm{~ms}$ (perekaman dengan ukuran kotak 32'). Latensi gelombang VEP pada studi ini cenderung lebih panjang dibandingkan sejumlah studi lain di Asia. Sharma dkk mendapatkan rerata latensi P100 adalah $88,31 \pm 8,799 \mathrm{~ms}$ dan $88,788 \pm 8,984 \mathrm{~ms}$ pada perempuan dan 93,214 $\pm 10,656 \mathrm{~ms}$ dan $93,41 \pm 10,628$ ms pada laki-laki (mata kiri dan kanan berturut-turut). Pada studi Shibasaki dkk latensi P100 adalah 92,5 $\pm 4,44 \mathrm{~ms}$, sedangkan Tandon yaitu
Shibasaki tidak menyebutkkan jenis layar stimulus. Perekaman dengan monitor tabung memiliki latensi yang lebih cepat, tetapi perbedaan itu seharusnya dapat dihilangkan dengan kalibrasi. Pada studi-studi tersebut juga tidak disebutkan pencahayaan ruangan yang digunakan. ${ }^{15,18}$

Kemungkinan perbedaan akibat faktor subjek seperti usia dan visus pada penelitian ini dapat disingkirkan, berdasarkan tidak adanya korelasi antara usia dan visus dengan parameter VEP. Adanya perbedaan tersebut dapat disebabkan oleh beberapa kemungkinan, antara lain perbedaan alat yang digunakan, keakuratan kalibrasi pada alat, serta faktor teknis yang tidak disebutkan pada metode studi-studi sebelumnya, seperti frekuensi stimulus.

Namun hasil latensi P100 penelitian ini serupa dengan Celesia dkk yang menggunakan 
metode Queen Square dalam penempatan elektroda, yaitu rerata latensi P100 98,7 $\pm 5 \mathrm{~ms}$. Demikian pula Tobimatsu di Asia dengan metode Queen Square, yaitu $102,6 \pm 3,5$, dan Guthkelch dkk $100,04 \pm 3,95 \mathrm{~ms}$ yang menggunakan metode $10-20 .{ }^{19-21}$

Perbedaan nilai normal dari satu studi dengan studi lainnya ini disebabkan oleh berbagai faktor, antara lain perbedaan karakteristik pasien, belum adanya standar yang seragam dari berbagai teknik perekaman serta perbedaan instrumen yang digunakan. Oleh karena itu, di setiap laboratorium pemeriksaan VEP diperlukan referensi nilai normal masing-masing. ${ }^{22}$

Pada perekaman dengan ukuran kotak 32', amplitudo gelombang P100 pada laki-laki adalah $7,76 \pm 3,196 \mathrm{mV}$ dan perempuan $11,32 \pm 5,319 \mathrm{mV}$. Nilai amplitudo ini tidak jauh berbeda dengan nilai studi-studi sebelumnya, yaitu rerata berkisar antara $6,5-10 u{ }^{19-26}$

Rerata perbedaan latensi intraokular pada studi ini adalah $4,23 \pm 2,986 \mathrm{~ms}$ pada laki-laki dan $3,98 \pm 3,129 \mathrm{~ms}$ pada perempuan, dengan nilai maksimum 14,3. Perbedaan latensi intraokular terbesar ini terjadi pada subjek dengan visus yang relatif kurang baik (20/100). Stockard juga didapatkan $90 \%$ subjek studi dengan perbedaan latensi intraokular $<5 \mathrm{~ms}$ dan nilai maksimal $9,9 \mathrm{~ms}$. Namun tidak ada perbedaan bermakna parameter ini antar subjek laki-laki dan perempuan, serupa dengan hasil studi Stockard. ${ }^{25}$

Rasio amplitudo interhemisfer pada studi ini berkisar antara $1,48 \pm 0,392$ pada laki-laki dan $1,53 \pm 0,559$ pada perempuan. Harmony mendapatkan rasio amplitudo interhemisfer pada 90\% sampel $<1,4 .{ }^{27}$

Penelitian ini juga mendapatkan perbedaan bermakna nilai latensi gelombang P100 pada perekaman dengan ukuran kotak 16' dan 32', tetapi tidak berbeda bermakna pada amplitudo. Hasil ini juga serupa dengan Tobimatsu dan Sokol. ${ }^{21,28} \mathrm{Hal}$ ini dapat disebabkan oleh perbedaan kapasitas sistem visual manusia dalam memproses frekuensi spasial yang diwakili oleh ukuran kotak. ${ }^{28}$

Nilai batas atas untuk latensi P100 penelitian ini adalah $117 \mathrm{~ms}$ dan $119 \mathrm{~ms}$ berturut turut untuk laki-laki dan perempuan pada perekaman dengan ukuran kotak 32'. Hasil ini serupa dengan Chiappa yang sering digunakan sebagai rujukan nilai normal $\operatorname{VEP}(<117,6 \mathrm{~ms})$ dan lebih panjang dari hasil Celesia, yakni $112 \mathrm{~ms} .{ }^{6,19}$

Penelitian ini tidak mendapatkan perbedaan rerata latensi gelombang P100 yang bermakna antara laki-laki dan perempuan, tetapi berbeda pada rerata amplitudo P100 antara laki-laki dan perempuan pada perekaman dengan ukuran kotak 16' maupun 32'. Hal ini sesuai dengan penelitian Celesia dkk, Mitchell dkk, dan Tandon dkk. ${ }^{19-27}$ Penelitian ini seperti halnya studi lain, mendapatkan perbedaan ukuran lingkar kepala yang signifikan antara laki-laki dan perempuan, tetapi tidak berbeda bermakna pada rerata latensi. Hal ini diduga karena perbedaan rerata lingkar kepala antara laki-laki dan perempuan pada studi ini hanya sebesar $1,18 \mathrm{~cm}$. Walaupun perbedaan ini signifikan secara statistik, tetapi secara klinis perbedaan ini belum tentu signifikan.

Sebagai perbandingan pada studi Gutkelch di Amerika dan Sharma di India, terdapat perbedaan rerata latensi gelombang P100 yang signifikan pada subjek laki-laki dan perempuan dan perbedaan rerata lingkar kepala antar subjek berdasarkan jenis kelamin berturut turut $3,19 \mathrm{~cm}$ dan $1,67 \mathrm{~cm}$. Selain itu, hal ini juga mungkin dapat disebabkan adanya faktor lain yang memengaruhi perbedaan latensi gelombang VEP laki-laki dan perempuan selain faktor ukuran kepala. ${ }^{15,20}$

Keterbatasan studi ini adalah modalitas yang digunakan dalam menyingkirkan kriteria eksklusi dari populasi target. Pada studi ini populasi target diseleksi menjadi subjek studi berdasarkan kriteria inklusi dan eksklusi yang diperoleh dari anamnesis dan pemeriksaan fisik sederhana. Idealnya dilakukan beberapa pemeriksaan penunjang seperti pemeriksaan laboratorium, pemeriksaan radiologis seperti pencitraan otak, maupun pemeriksaan mata atau neurooftalmologi yang lebih akurat, seperti penggunaan kampimetri dalam mengevaluasi lapang pandang.

\section{KESIMPULAN}

Pada perekaman dengan ukuran kotak 32', nilai batas atas latensi gelombang P100 adalah 117 
milidetik pada laki-laki dan 119 milidetik pada perempuan. Nilai batas atas perbedaan latensi interokular adalah 10,96 milidetik pada laki-laki dan 10,2 milidetik pada perempuan.

Pada studi ini, tidak didapatkan perbedaan rerata amplitudo gelombang P100 yang bermakna $(\mathrm{p}>0,05)$ antara perekaman dengan ukuran kotak 16' dan 32', tetapi terdapat perbedaan yang bermakna pada rerata latensi P100 antara perekaman dengan ukuran kotak 16' dan 32'pada subjek laki-laki maupun perempuan.

Hasil studi ini dapat digunakan sebagai pedoman nilai normal pengukuran VEP di FKUI/ RSUPN Dr. Cipto Mangunkusumo dan laboratorium neurofisiologi lain di Indonesia dengan menggunakan parameter-parameter yang sesuai dengan studi ini.

\section{DAFTAR PUSTAKA}

1. Brown RH, Ropper AH. Adams and Victor's principles of neurology. Edisi ke-8. The McGrawHill Companies, Inc. 2005. h. 29-31.

2. Odom, JV, Bach M, Brigell M, Holder GE, McCulloch DL, Tormene AP. ISCEV standard for clinical visual evoked potentials (2009 update). Documenta Ophthalmologica. 2010;120(1):111-9.

3. Odom JV, Bach M, Barber C, Brigell M, Marmor MF, Tormene AP, Holder GE. Visual evoked potentials standard (2004). Documenta Ophthalmologica. 2004;108(2):115-23.

4. Misulis KE, editor. Spehlmann's evoked potential primer: visual, auditory, and somatosensory evoked potentials in clinical diagnosis. ButterworthHeinemann Medical. 1994. h. 1-188.

5. Walsh P, Kane N, Butler S. The clinical role of evoked potentials. J Neurol Neurosurg Psych. 2005;76(Supl 2);ii16-22.

6. Chiappa KH. Evoked potentials in clinical medicine. Edisi ke-3. Philadelphia: Lippincott-Raven; 1997.

7. Crell DJ. Visually evoked potentials. Dalam: Kolb H, Nelson R, Fernandez E, Jones B. Webvision: the organization of retina and visual system. Utah. 2015.

8. Wolsey DH, Larson SA, Creel D, Hoffman R. Can screening for optic nerve gliomas in patients with neurofibromatosis type I be performed with visualevoked potential testing? J AAPOS. 2006;10(4):307-11.

9. Di-Maggio G, Santangelo R, Guerrieri S, Bianco M, Ferrari L, Medaglini S, dkk. Optical coherence tomography and visual evoked potentials: which is more sensitive in multiple sclerosis? Multiple Sclerosis J. 2014;20(10):1342-7.
10. North K, Cochineas C, Tang E, Fagan E. Optic gliomas in neurofibromatosis type 1: role of visual evoked potentials. Pediatric Neurol. 1994;10(2):11723.

11. Jabbari B, Maitland CG, Morris LM, Morales J, Gunderson $\mathrm{CH}$. The value of visual evoked potential as a screening test in neurofibromatosis. Arch Neurol. 1985;42(11);1072-4.

12. Meinck HM, Adler L, Rader K, Conrad B. Delayed visual evoked potentials in chronic alcoholism. J Neurol. 1986;233(3):161-3.

13. Holmes MD, Sires BS. Flash visual evoked potentials predict visual outcome in traumatic optic neuropathy. Ophthalmic Plast Reconstr Surg. 2004;20(5):342-6.

14. Mahapatra AK, Bhatia R. Predictive value of visual evoked potentials in unilateral optic nerve injury. Surgical Neurol. 1989;31(5):339-42.

15. Sharma R, Joshi S, Singh KD, Kumar A. Visual evoked potentials: normative values and gender differences. J Clin Diagn Res. 2015;9(7):CC12-5.

16. Syaifudin M, Alatas Z, Rahardjo T. Penelitian antropometrik manusia Jawa dalam rangka penyusunan manusia acuan Indonesia. Prosiding Presentasi Ilmiah. Keselamatan Radiasi dan Lingkungan; 1996 Agustus 20-21; Jakarta; Standarisasi MP \& Radiasi-BATAN PK; 1996. h. 230-9.

17. Perhimpunan Ergonomi Indonesia. Data Antropometri Indonesia. Jakarta: Perhimpunan Ergonomi IndonesiaBadan Kerjasama Penyelenggara Pendidikan Tinggi Teknik Industri Indonesia; 2011.

18. Tandon OP, Sharma KN. Visual evoked potential in young adults; a normative study. Ind J Phyuol Pharmac. 1989;55(4).

19. Celesia GG, Kaufman D, Cone S. Effects of age and sex on pattern electroretinograms and visual evoked potentials. Electroencephal Clin Neurophysiol (Evoked Potentials Section). 1987;68(3):161-71.

20. Guthkelch AN, Bursick D, Sclabassi RI. The relationship of the latency of the P100 wave to gender and head size. Electroencephalogr Clin Neurophysiol. 1987;68:219-22.

21. Tobimatsu S, Kurita-Tashima S, NakayamaHiromatsu M, Akazawa K, Kato M. Age-related changes in pattern visual evoked potentials: differential effects of luminance, contrast and check size. Electroencephal Clin Neurophysiol (Evoked Potentials Section). 1993;88(1):12-9.

22. Allison T, Wood CC, Goff WR. Brain stem auditory, pattern-reversal visual, and short-latency somatosensory evoked potentials: latencies in relation to age, sex, and brain and body size. Electroencephal Clin Neurophysiol. 1983;55(6):619-36. 
23. Emmerson-Hanover R, Shearer DE, Creel DJ, Dustman RE. Pattern reversal evoked potentials: Gender differences and age related changes in amplitude and latency. Electroenceph Clin Neurophysiol. 1994;92:93-101.

24. Shih PY, Aminoff MJ, Goodin DS, Mantle MM. Effect of reference point on visual evoked potentials: clinical relevance. Electroencephal Clin Neurophysiol (Evoked Potentials Section). 1988;71(4):319-22.

25. Stockard JJ, Hughes JF, Sharbrough FW. Visually evoked potentials to electronic pattern reversal: latency variations with gender, age, and technical factors. Am J EEG Technology. 1979;19(4):171-204.
26. La Marche JA, Dobson WR, Cohn NB, Dustman RE. Amplitudes of visually evoked potentials to patterned stimuli: age and sex comparisons. Electroencephal Clin Neurophysiol (Evoked Potentials Section). 1986;65(2):81-5.

27. Harmony T, Ricardo J, Otero G, Fernandez G, Llorente S, Valdes P. Symmetry of the visual evoked potential in normal subjects. Electroencephal Clin Neurophysiol. 1973;35(3):237-40.

28. Sokol S, Moskowitz A, Towle VL. Age-related changes in the latency of the visual evoked potential: influences of check size. Electroencephal Clin Neurophysiol. 1981;51(5):559-62. 